\title{
Assessing fracture occurrence using "weighted fracturing density": a step towards estimating rock instability hazard
}

\author{
M. Jaboyedoff ${ }^{1,2}$, F. Baillifard ${ }^{1,3}$, F. Philippossian ${ }^{1,4}$, and J.-D. Rouiller ${ }^{1}$ \\ ${ }^{1}$ CREALP - Research Centre on Alpine Environment, Industrie 45, 1951 Sion, Switzerland \\ ${ }^{2}$ Quanterra, Ch. Tour-Grise 28, 1007 Lausanne, Switzerland \\ ${ }^{3}$ Institute of Geology and Paleontology, University of Lausanne, BFSH2, 1015 Lausanne, Switzerland \\ ${ }^{4}$ Bureau d'études géologiques, Le Botza, 1963 Vétroz, Switzerland
}

Received: 2 September 2003 - Revised: 5 December 2003 - Accepted: 5 January 2004 - Published: 9 March 2004

Part of Special Issue "Landslide and flood hazards assessment"

\begin{abstract}
Based on the assumption that major class of rock instabilities are created by discontinuities, a method is proposed to estimate the fracture density by means of a digital elevation model (DEM). By using the mean orientation, the mean spacing and the mean trace length of discontinuity sets potentially involved in slope instabilities and a DEM, it is possible to calculate the mean number of discontinuities of a given set per cell of the DEM. This would allow for an estimation of the probability of the presence of at least one discontinuity in a given area or simply in a topographic cell of the DEM. This analysis highlights sites potentially affected by rockslides within a region. Depending on the available data, the mean number can be calculated either by area, or along a line parallel to the mean apparent spacing. The effective use of the probability of occurrence is dependent on the size of the discontinuities because short and closely spaced discontinuities will have a $100 \%$ probability of occurrence in each favorable location. The a posteriori prediction of a recent rockslide is discussed as an example.
\end{abstract}

\section{Introduction}

Digital elevation models (DEM) provide several possibilities for landforms analysis (Carrara and Guzzetti, 1995; Montgomery et al., 1998) and slope stability analysis (Pack et al., 1998; Guzzetti et al., 1999; Crosta et al., 2001). Rock slope stability is essentially controlled by fractures (Selby, 1993), especially in relation to their densities and orientations. As proposed by Hoek and Bray (1981), rock slopes may be subdivided into structural areas with regard to slope stability. Considering structural and geological features, structural regions are homogeneous insofar as the discontinuities are similar in number of sets, orientation and density. In each of these areas, regardless of whether geomechanical criteria are considered, the potential kinematics of failure like plane or wedge sliding, or toppling can be pointed out. Methods used to predict areas affected by potential sliding mechanisms can be carried out either manually, or by using computerized algorithms (Wagner et al., 1988; Rouiller et al., 1998; Jaboyedoff et al., 1999; Gokceoglu et al., 2000; Meentemeyer and Moody, 2000; Günther, 2003).

This paper deals with the detection and estimation of the mean number of discontinuities by surface unit or along a line, or the probability of the presence of fracture sets that may produce rockslides. Our approach consists of 3 steps: (1) defining the homogeneous structural domains, (2) identifying and characterizing the discontinuity sets, and (3) comparing the structural features with the topography by means of a DEM. The results may be used in the generation of hazard maps provided that the importance of the discontinuity sets for stability is weighted. Hence, if the mean orientation, mean spacing and mean trace length of a discontinuity set are known, it is possible to determine the number of discontinuities for each topographic surface area. In doing so, the probability of the presence of at least one discontinuity or wedge on a surface or along a line can be estimated. Although many works have previously been published on the computerized detection on large areas and hazard assessment of landslides (Gupta et al., 1999; Guzzetti et al., 1999), but very few have dealt with the automatic analysis of rock slopes on large areas (Wagner et al., 1988; Gokceoglu et al., 2000; Meentemeyer and Moody, 2000; Günther, 2003).

The proposed method, which requires little data acquisition for an experienced geologist, is a tool for detecting potential rockslide instabilities and assessing their hazard. 


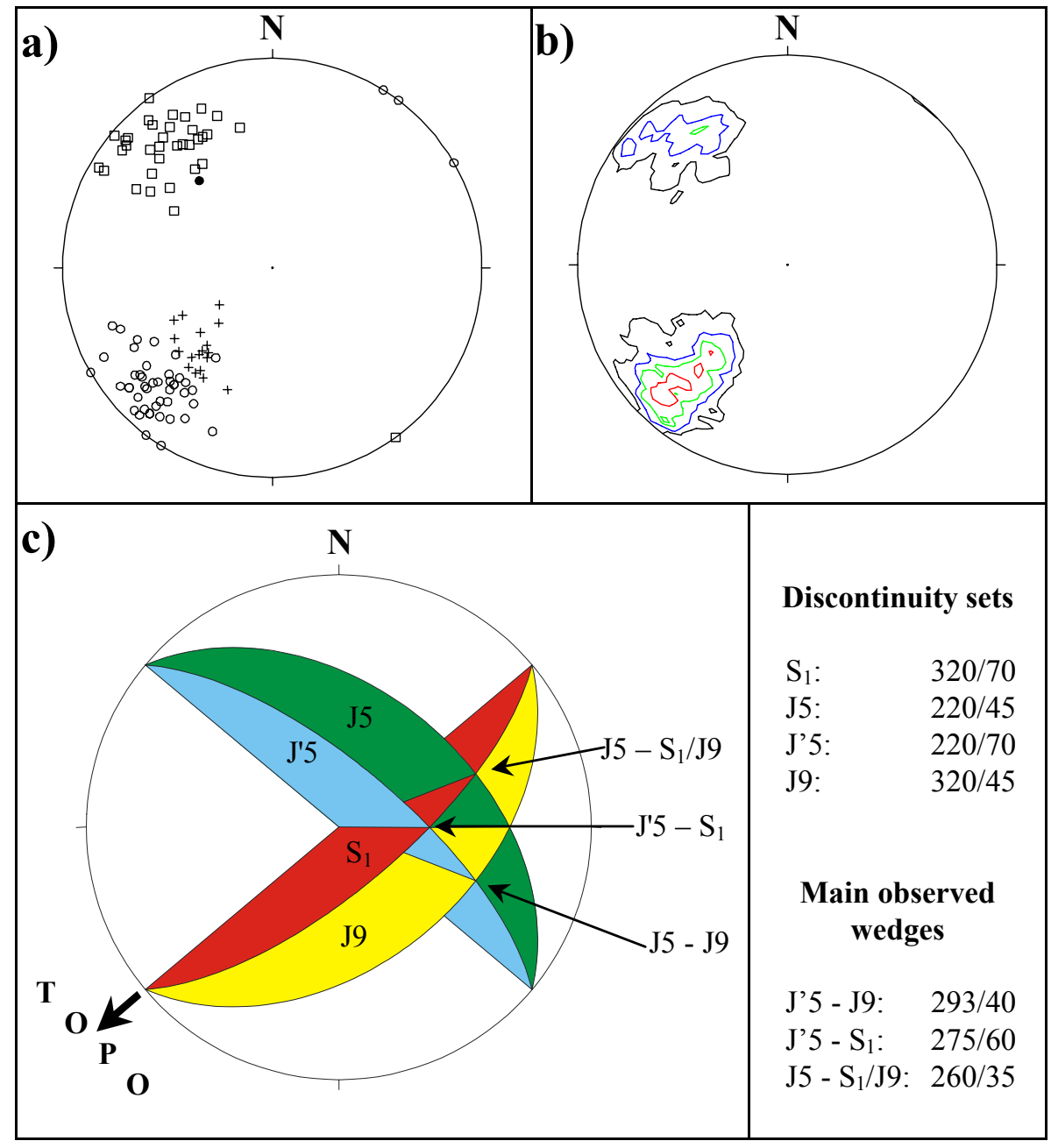

Fig. 1. Area of Fionnay (Valais, Switzerland). (a): Measured discontinuities (99 data: J5: circles; J'5: crosses; J9: black dots; $S_{1}$ : squares); (b): contouring of (a) data highlighting the most important discontinuity sets; (c): simplified stereonet (SchmidtLambert equal area, upper hemisphere), which synthesizes the structural features of a homogeneous fractured zone. Note that the J5 and J'5 are distinguished because the field observations indicate that those two sets are intersecting. J9 is not represented on a) and on b) because it has been clearly identified (crossing $S_{1}$ ) on the field but with too few data.

\section{Methods for sampling the geometrical characteristics of the discontinuities}

The geometrical characterization of the discontinuities, such as their spacing, trace length, mean and/or distributions can be determined by several methods yielding more or less detailed information. A review of the main methods can be found in Priest (1993).

Trace lengths have been estimated by employing distribution assumptions (Priest and Hudson, 1981). In these cases, they can be estimated by counting them on rectangular (Pahl, 1981) or circular windows (Mauldon et al., 2001). Other methods using two or more photographs of an outcrop allow the estimation of orientation, fracturing density and trace length (Thomas et al., 1987; Crosta, 1997). Detailed digital elevation model may be used to characterize discontinuity sets (Froldi, 2000). A more sophisticated and time consuming approach employs the use of software, such as Fracman (Dershowitz et al., 1996) or Resoblok (École des Mines de Nancy, 2000), which allows a complete characterization of discontinuities using numerical simulations (Baroudi et al., 1990; Starzec and Andersson, 2002).
The present method uses simple estimates of the mean characteristics of discontinuity sets. The first step consists in defining homogeneous structural domains, where geological structures, lithologies and fracturing show constant properties, i.e. orientation, spacing, trace length, undulation, infilling material and aperture. In other words, this is an area where rock instabilities are driven by an identical mechanism that could also be controlled by slope morphology.

The second step consists of a field survey of the discontinuities (Hoek and Bray, 1981; LaPointe and Hudson, 1985; Giani, 1992; Priest, 1993; Jaboyedoff et al., 1996). This survey can be more or less detailed, depending on the goal of the study. An estimation of the fracturing density requires three parameters for each discontinuity set: the mean orientation, mean spacing and mean trace length (CREALP, 2003; Delèze et al., 2003). Simple procedures used to determine these parameters are outlined.

\subsection{Mean orientation}

Each structural domain should be characterized by a single stereonet displaying the mean orientation of sets (Fig. 1). The determination of the mean orientation of a discontinuity 


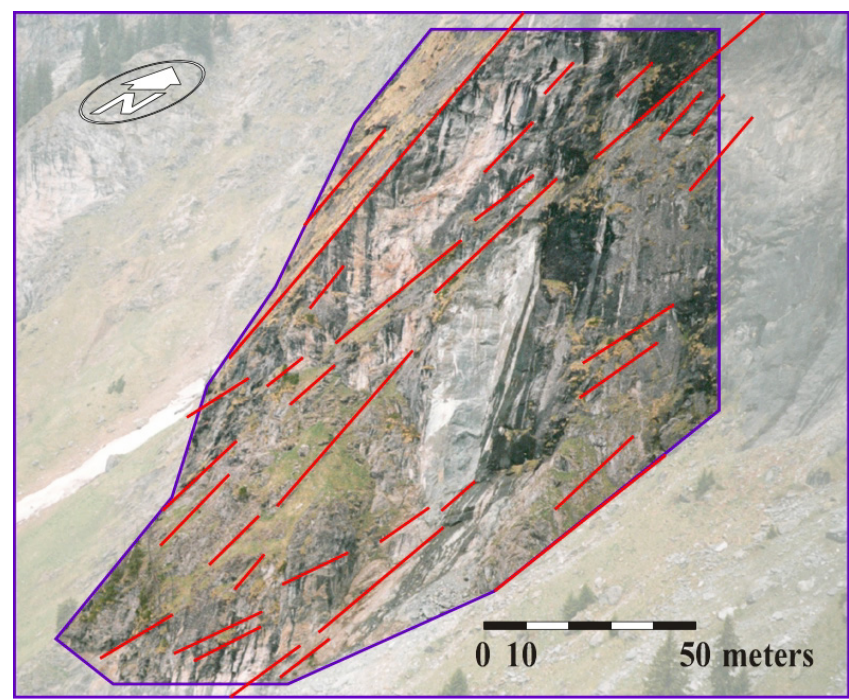

Fig. 2. Sampling window made from a photograph of the Fionnay cliff containing estimates of the different parameters described in the text. The J5 discontinuity set is presented. Note that the geometry of the window, elongated as J5 favors its individuation.

set requires several structural measurements. Contouring procedures may be applied in order to find the most significant orientations (Hoek and Bray, 1981). During data acquisition, the orientation of the sampled areas has to be noted, because contouring procedures can bias the fracture density sampling. For example, data sampled along a scanline are biased since the discontinuity frequency is dependent on the angle between the discontinuity set and the scanline. The density point of the stereonet can be corrected using Terzaghi correction (Terzaghi, 1965; Priest, 1993).

\subsection{Mean number of traces in a sampling window}

Because third dimension of the structure is not easily accessible, surface observations are the only data available. Trace lengths may be estimated from a sampling window by dividing the total length of the traces that appear in the window by the number of contained traces (Fig. 2). This number however does not correspond directly to the number of counted traces and must be corrected since some of them are partially displayed. Assuming an infinite imaginary outcropping surface, which is filled periodically by identical sampling windows, each of the traces beginning in one window will, on average, end in another. Consequently, the number of partially contained traces $\left(n_{1}\right)$ must be divided by two. The traces completely crossing the window are not taken into account since they are counted in two other virtual windows. The traces for which both ends are included in the window $\left(n_{0}\right)$ are all counted. On average, the number $(n)$ of trace lengths included in a window is given by:

$n \approx n_{0}+\frac{n_{1}}{2}$

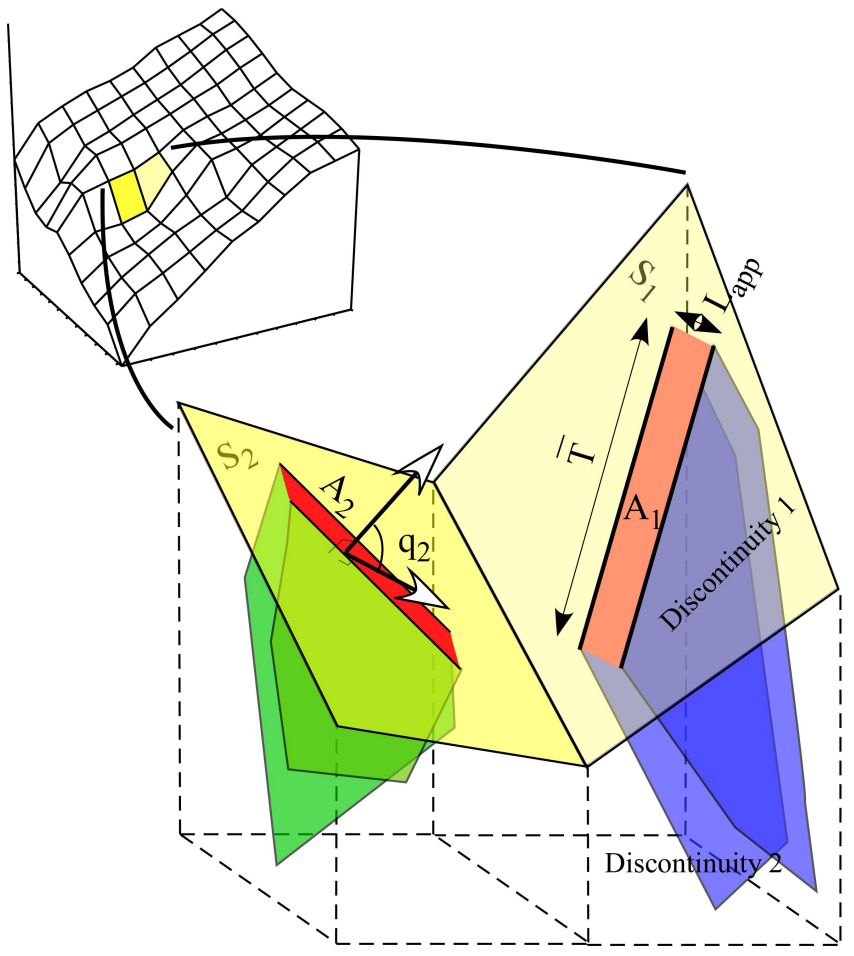

Fig. 3. Illustration of the mean apparent lateral surface $\bar{s}$ (quoted as $A_{1}$ and $A_{2}$ ) using a DEM with a squared grid. The ratio $A / S$ gives the mean number of discontinuities per surface unit. The surface orientation is generally estimated from the center of the topographic face since it is not a true planar surface.

\subsection{Mean trace length}

Being $T_{i}$ the length of the $i^{\text {th }}$ discontinuity trace, observed in the sampling window, and $T_{\text {tot }}$ the total trace length displayed, dividing $T_{\text {tot }}$ by $n$ gives the mean trace length $\bar{T}$ :

$\bar{T}=\frac{\sum_{\text {window }} T_{i}}{n}=\frac{T_{\text {tot }}}{n}$

$\bar{T}$ could depend on the shape of the fracture, but for simplification we assume that for a given discontinuity set, $\bar{T}$ is identical for each orientation of the sampling window (Fig. 3). On the other hand, the accuracy of the estimation of the mean trace length depends on the orientation of the observation surface since the number of discontinuities is different for an identical observation area having different orientations (see Sect. 2.5).

\subsection{Mean spacing, frequency and lateral surface}

Assuming that $\bar{L}$ is the perpendicular mean spacing between the discontinuities, the discontinuity frequency $\lambda$ is given by:

$\lambda=\frac{1}{\bar{L}}$

On the other hand, the product of the mean discontinuity spacing $\bar{L}$ and the mean trace length $\bar{T}$ gives the mean 


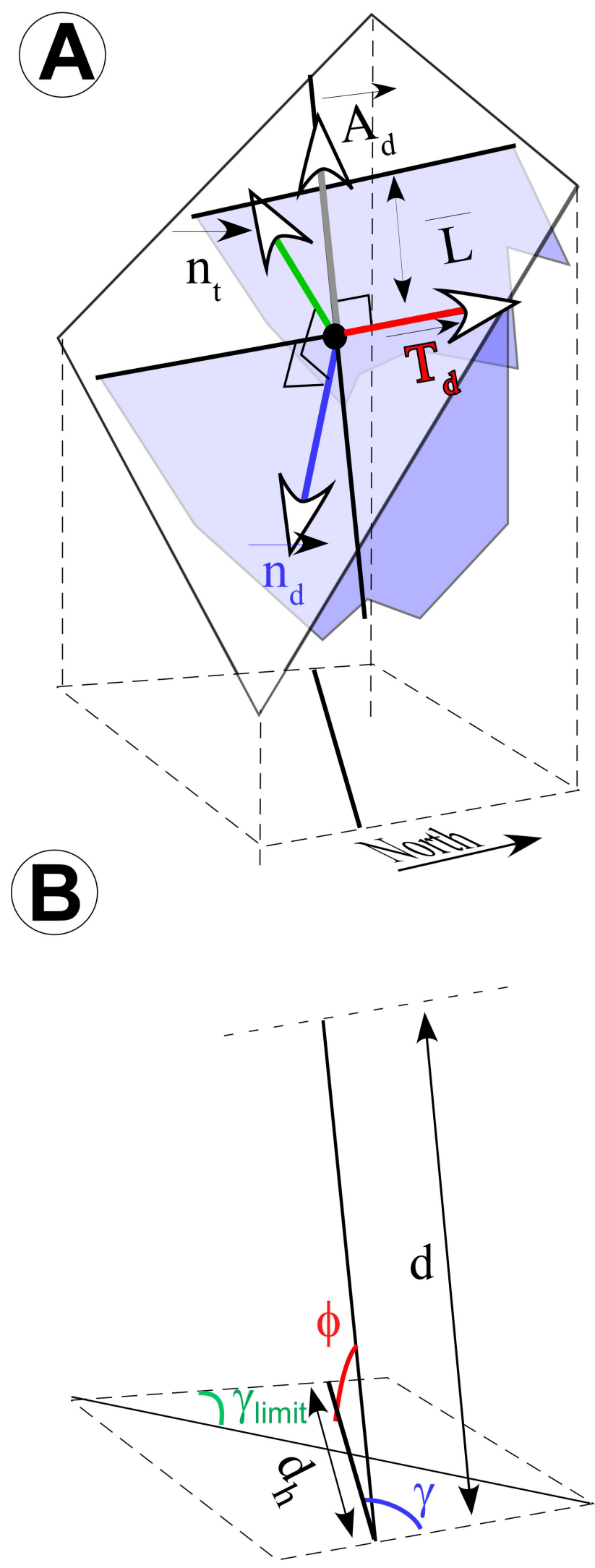

Fig. 4. Definition of the different vectors used to calculate the linear frequency (see text for explanations). discontinuity lateral surface, $\bar{s}$ (Fig. 3):

$\bar{s}=\bar{L} \bar{T}$

Thus, the area of the sampling window $S_{\text {obs }}$ is equal to the product of the number of discontinuities $(n)$ by $\bar{s}$ :

$S_{\mathrm{obs}}=n \bar{s}=n \bar{L} \bar{T}$

Using the previous formula, $\lambda$ can also be obtained by calculating the total length of the observed discontinuity traces:

$\lambda=\frac{1}{\bar{L}}=\frac{n \bar{T}}{n \bar{L} \bar{T}}=\frac{T_{\text {tot }}}{S_{\text {obs }}}$

\subsection{Correction for a non-perpendicular sampling window}

A correction is applied to the above formulae when, as it is usually the case, the observation surface is not perpendicular to the discontinuities. Since the trace length is assumed not being affected by the orientation of the observations, only $\bar{L}$ and $\lambda$ must be corrected.

If $\bar{L}_{\text {app }}$ is the apparent discontinuity spacing and $\theta$ the angle between the normal to the discontinuities and the normal to the observation surface, $\bar{L}_{\text {app }}$ is linked to $\lambda$ by:

$\bar{L}_{\text {app }} \times \sin \theta=\bar{L} \quad$ or $\lambda \times \sin \theta=\lambda_{\text {app }}$

For spacing data sampled along a scanline, assuming $\beta$ the angle between the normal to the discontinuities and the orientation of the scanline, for a plane $\bar{L}_{\text {app }}$ is given by:

$\bar{L}_{\text {app }} \times \cos \beta=\bar{L} \quad$ or $\lambda \times \cos \beta=\lambda_{\text {app }}$

\section{Use of geometrical characteristics: probabilistic approach}

Considering a DEM with a rectangular mesh size equal to $\Delta x \Delta y$, a plane approximates the orientation and surface $(S)$ of the topographic cell. $S$ is then equal to $\Delta x \Delta y / \cos \sigma$, where $\sigma$ is the dip angle of the topographic cell (Fig. 4).

\subsection{Number and probability of discontinuities within an} area

The average number of discontinuities $\left(N_{s}\right)$ contained within a cell of surface $S$, using Eqs. (4) and (7) is given by:

$$
\begin{aligned}
N_{s} & =S /\left(T \bar{L}_{\text {app }}\right)=S \times \sin \theta / \bar{s} \\
& =(\Delta x \Delta y) \times \sin \theta /(\bar{s} \times \cos \sigma)
\end{aligned}
$$

Considering a surface area of topography constituted by several DEM cells, $N_{s}$ is equal to the sum of the contributions of all orientations, thus:

$N_{s}=\frac{1}{\bar{s}} \sum S_{i} \sin \theta_{i}$

where the index $i$ refers to each topographic cell. This result is independent of the sliding direction. 
Assuming a random (Poisson) distribution of discontinuity lateral surfaces $\bar{s}$, the probability of finding at least one discontinuity in a surface area of topography constituted by one or several cells can be estimated using the following equation:

$F_{S}(x)=1-e^{-N_{s}}$

\subsection{Number and probability of discontinuities along a line}

The previous method does not take the explicitly rectangular shape of the topographic facet of the DEM into account, but only its surface. Thus, if the perpendicular to the trace of the discontinuity is oblique to the cell (i.e. $x$ and $y$ components are both nonzero), it is not incorporated within the $N_{s}$ calculation. Along an oblique direction, the average number of discontinuities increases. An alternative method consists of estimating the number of discontinuities in the direction along the minimum apparent spacing for each cell of the grid. This is calculated using the vectors $\boldsymbol{n}_{t}, \boldsymbol{T}_{d}, \boldsymbol{n}_{d}, \boldsymbol{A}_{d}$, which correspond to unitary vectors normal to the topography, parallel to the trace of the discontinuity on the facet of the topography, normal to the discontinuity set and parallel to the minimum apparent spacing on the topographic cell, respectively (Fig. 4). The trace direction is obtained by the cross product $(x)$ of the normal to the topographic cell and the normal to the discontinuity:

$\boldsymbol{T}_{d}=\boldsymbol{n}_{t} \times \boldsymbol{n}_{d} \quad$ and $\quad \boldsymbol{A}_{\mathrm{d}}=\boldsymbol{n}_{\mathrm{t}} \times \boldsymbol{T}_{\mathrm{d}}$

Thus, the apparent spacing $\left(\bar{L}_{\text {app }}\right)$ on the topographic facet is given by the mean spacing divided by the absolute value of the cosine of the angle between $\boldsymbol{A}_{d}$ and $\boldsymbol{n}_{d}$ (or the scalar product of both):

$\bar{L}_{\text {app }}=\frac{\bar{L}}{\left|\boldsymbol{n}_{d} \cdot \boldsymbol{A}_{d}\right|}$

The mean number of discontinuities which can be found is given by the maximum $d / \bar{L}_{\text {app }}$, where $d$ is the length in the $\boldsymbol{A}_{d}$ direction on a topographic facet. $d$ is maximal if it is measured between two opposite sides and not between two adjacent sides of the topographic facet. If $\Delta x$ and $\Delta y$ represent the mesh size in the $x$ and $y$ directions, the horizontal angle of the diagonal of the mesh is given by: $\gamma_{\text {limit }}=\arctan (\Delta x / \Delta y)$. Now consider the length $\left(d_{h}\right)$ that represents the projection $d \times \boldsymbol{A}_{d}$ on the horizontal. An estimate of $d_{h}$ depends on its orientation $(\gamma)$ relative to $\gamma_{\text {limit }}$. Let $A_{x}, A_{y}$, and $A_{z}$ represent the $\boldsymbol{A}_{d}$ coordinates and $\phi$ the angle with the horizontal. $\gamma$ is equal to $\arctan \left(A_{x} / A_{y}\right)$, and must be compared to $\gamma_{\text {limit. }}$. Thus, $d_{h}=\Delta y / \cos \gamma$ where $\gamma \leq \gamma_{\text {limit }}$ or $d_{h}=\Delta x / \sin \gamma$ where $\gamma>\gamma_{\text {limit }}$. Knowing that $\cos \phi=\sqrt{\left(A_{x}^{2}+A_{y}^{2}\right) /\left(A_{x}^{2}+A_{y}^{2}+A_{z}^{2}\right)}$ and that $d_{h}=d \cos \phi, d$ can be calculated.

The mean number of discontinuities is then $N_{L}=\bar{L}_{\text {app }} / d$ and, by analogy with Eq. (11), in the case of one cell, the probability of finding at least one discontinuity in the topographic facet is given by:

$F_{L}(x)=1-e^{-N_{L}}$

\section{Application to rockslide hazard assessment}

\subsection{Detection of potential sliding zones}

The Matterocking software (CREALP, 2003) employs the aforementioned geometrical characteristics of the discontinuities (orientation, spacing and trace length) to detect potential sliding zones. The results are useful for rockslide hazard assessment. Three main result types can be produced and stored in grid files:

(1) Comparison of the mean orientation of a given set of discontinuities with a DEM, to determine areas where the set may induce rockslides (Fig. 5a).

(2) The expected mean number of discontinuities $\left(N_{s}\right)$ or their probability of occurrence $\left(F_{S}\right)$ in each mesh of the DEM (Fig 5b). Within the area that allows planar sliding (Fig. 5b), the mean number of discontinuities ( $N_{s}$ or $F_{s}$ ) provides information on the potential occurrence of rockslides delimited by a discontinuity set.

(3) The expected mean number of discontinuities $\left(N_{L}\right)$ or their probability of occurrence $\left(F_{L}\right)$ along their minimum apparent spacing.

Grid files may be exported either in Surfer (Golden Software) or ArcView (ESRI) ASCII grid file formats. In the example presented (Fig. 5), $N_{s}$ is estimated only in the areas where the condition of sliding is verified (areas where the dip of the discontinuity set is less steep than the topographic slope in the sliding direction, Fig. 5a). A comparison of the results obtained in a homogeneous area with the observed small sliding instabilities (sliding on J'2) determined by a field survey demonstrates the efficiency of the method. Most of the active zones are located within the topographic sectors theoretically affected by potential sliding (Fig. 5a). The gaps in the detection of a few active zones may be attributed to the fact that in the present state the method does not take into account a range in variation of the sliding direction. This means that there is no range of tolerance in the sliding direction and slope dip direction values, i.e. angle between slope dip direction and joint dip direction.

The calculation of the number of discontinuities within a DEM cell does not yield any information concerning the potential volume involved. One way to provide this information is to take into account the direction of the sliding in order to weight the count of the number of discontinuities by unit area. The previous method will assign $N_{S}$ the same value for identical $\theta$ values either if the topography is parallel or nearly perpendicular to the sliding direction. If $\delta$ is the angle between the direction of sliding and the normal to the topography, $N_{s}$ can be replaced by:

$N_{V}=\cos \delta(\Delta x \Delta y) /(\bar{s} \cos \sigma)$

In the case where the topographical facet is nearly parallel to the direction of sliding, $N_{V}$ tends to zero while $N_{s}$ is not affected by $\delta$. This is compatible with the fact that, in this 

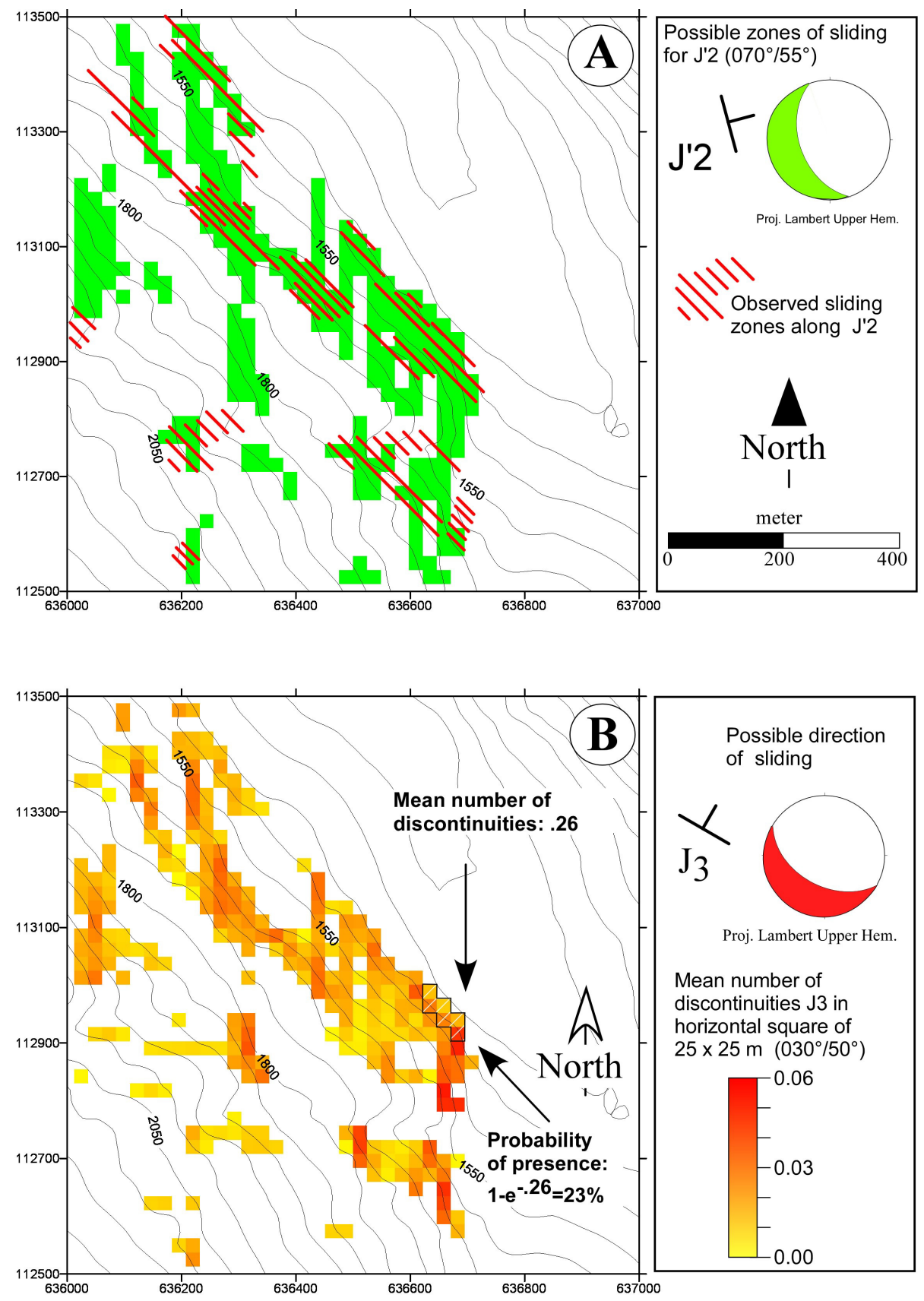

Fig. 5. Examples of application in the Saastal (Switzerland) (modified after Jaboyedoff et al., 1999). Knowing the mean topographic orientation, the possible direction of sliding can be deduced from a stereonet; (a) the green area represents the topographic domain where the discontinuity set J'2 $\left(070^{\circ} / 55^{\circ}\right)$ could induce small rockslides. The red lines indicate the observed small rockslide mechanism on J'2 discontinuities, producing activity; (b) the yellow-red scale displays $N_{S}$ for the $\mathrm{J} 3$ discontinuity set $\left(030^{\circ} / 50^{\circ}\right) . \bar{T}=220 \mathrm{~m}$ and $\bar{L}=100 \mathrm{~m}$. The number of discontinuities counted in the outlined zone is 0.26 , thus the probability of finding at least one discontinuity is $23 \%$. $\mathrm{J} 3$ that can generate a rockslide with a large volume.

case, no rock volume will be involved in a rockslide. A probability $\left(F_{V}\right)$ can be also calculated.

It should be noted that $\bar{s}$ can be replaced by a smaller value that takes into account the lateral dimension of the potential rock instability.
Matterocking allows for the detection of either plane or wedge sliding. In the latter case, the discontinuity section is replaced by the surface, defined by using the orientation and mean spacing of both discontinuity sets. The calculation of the number or probability of wedges is similar to the calculation of $N_{V}$, and $F_{V}$. 


\subsection{Principle of relative hazard rating}

The rockslide instability hazard $(H)$ can be estimated using a relative scale based on $N_{s}, F_{s}$ or $N_{L}, F_{L}$ or $N_{V}, F_{V}$. The probability of the presence of a potentially dangerous sliding structure can be estimated by $F_{S}$ for any surface. Assuming the existence of dangerous structures, the hazard assessment requires an estimate of the probability of failure $\left(P_{f}\right.$, having a frequency unit) of a rock failure at the instability location. The hazard $H$ can then be estimated by:

$H=F_{s} P_{f}$

Now, assuming that $P_{f}$ is difficult to obtain or that $P_{f}$ is constant within a region (Hantz et al., 2001; Dussauge-Peisser et al., 2002), $F_{s}$ may be considered as a relative hazard value, in addition to $N_{s}, N_{L}, N_{V}, F_{V}$ and $F_{L}$.

The use of $N$ or $F$ as a hazard rating is dependent on $\bar{L}, \bar{T}$ or $\bar{s} . F_{S}$ can be only used if the structure can be geometrically contained within the surface considered. This must be taken into account for the computation of $F_{s}$ within the DEM cell facet. The contouring of an area using Eq. (10) allows for the application of $F_{S}$ to a specific zone of a relevant surface. This problem does not occur for $N_{L}$ or $F_{L}$.

\subsection{Example of a rockslide back-analysis}

On 4 August 1994 during the night, the region of Fionnay (Valais, Switzerland) suffered a rockslide of about $2000 \mathrm{~m}^{3}$ (Baillifard, 1998) (Fig. 6). The rockslide failed to reach the inhabited area because it was stopped by the blocks of an ancient rockslide. Field observations indicate that the area surrounding the 1994 rockslide can be considered as a structurally homogeneous domain within greenschist rocks. Structural analysis based on a field survey was performed to determine the failure mechanism. A back analysis shows that the rock mass slides on a pre-existing J5 discontinuity. J5 discontinuities dip on average in the direction $220^{\circ} / 45^{\circ}$ and rockslides are facilitated due to their real planar shape. Water often seeps out of J5 discontinuities, showing their continuity and aperture that can reach up to $10 \mathrm{~cm}$. A J'5 discontinuity $\left(220^{\circ} / 70^{\circ}\right)$ manifests as tension cracks, while the foliation $\left(320^{\circ} / 70^{\circ}\right)$ and $\mathrm{J} 9$ discontinuities act as shear planes (Figs. 1 and 6). Rockslide created by J'5 involves smaller volumes. Scree deposits below the cliff containing J5 or J'5 discontinuities indicate possible instability or activity.

J5 discontinuities are the main destabilizing features of the rock slope. This discontinuity set was therefore compared to the topography in an effort to validate the proposed method and to detect other potential sliding zones.

The mean trace length and mean spacing were estimated with a sampling window using Eqs. (1) to (6). A picture was used as a base for the sampling window (Fig. 2). The mean spacing determined is $50 \mathrm{~m}$ and the mean trace length reaches $60 \mathrm{~m}$.

These characteristics where compared to the topography using a $25 \times 25 \mathrm{~m}$ DEM established before the rockslide. The
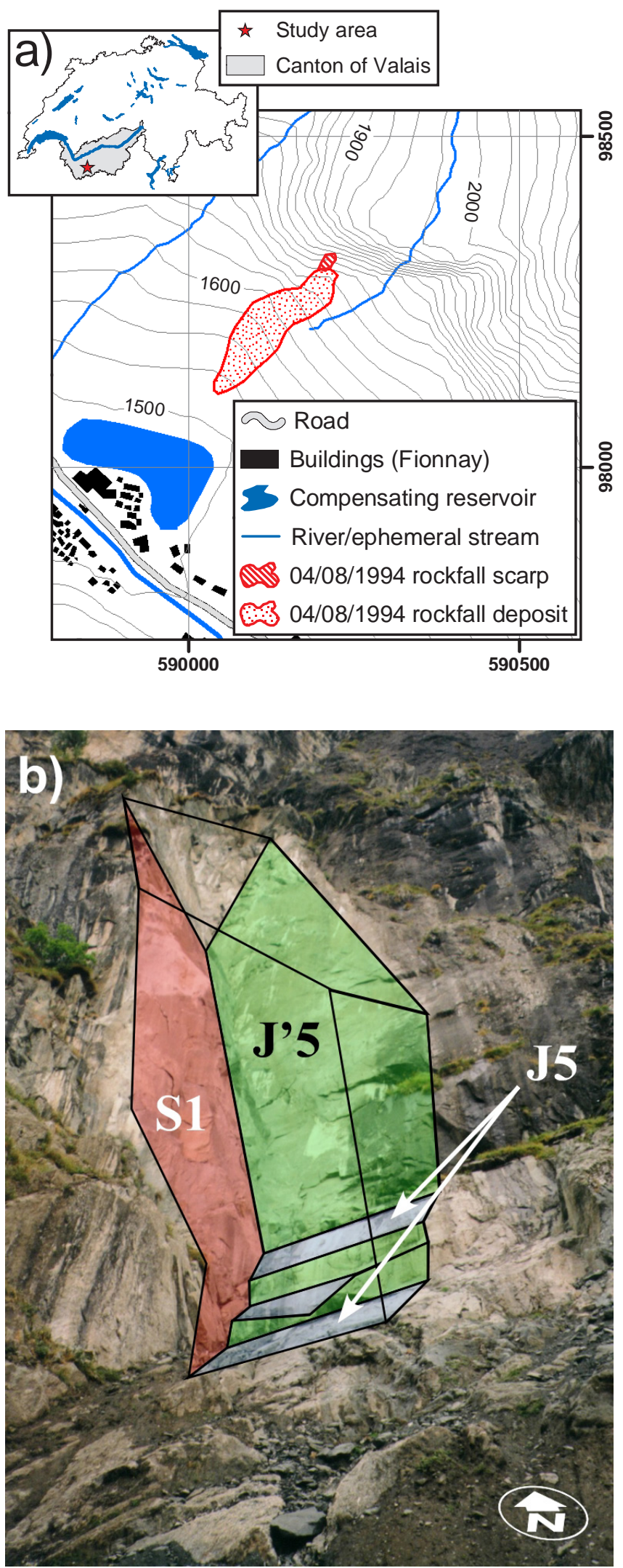

Fig. 6. (a) Location of the rockslide (1994) near Fionnay; (b) snapshot highlighting the mechanism of the rockslides. 
Surface

Number

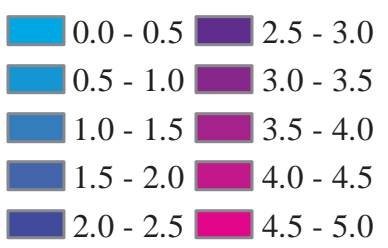

Probability

$0 \%-10 \% \square 50 \%-60 \%$

$10 \%-20 \% \square 60 \%-70 \%$

$20 \%-30 \% \square 70 \%-80 \%$

$30 \%-40 \% \quad 80 \%-90 \%$

$40 \%-50 \% \square 90 \%-100 \%$
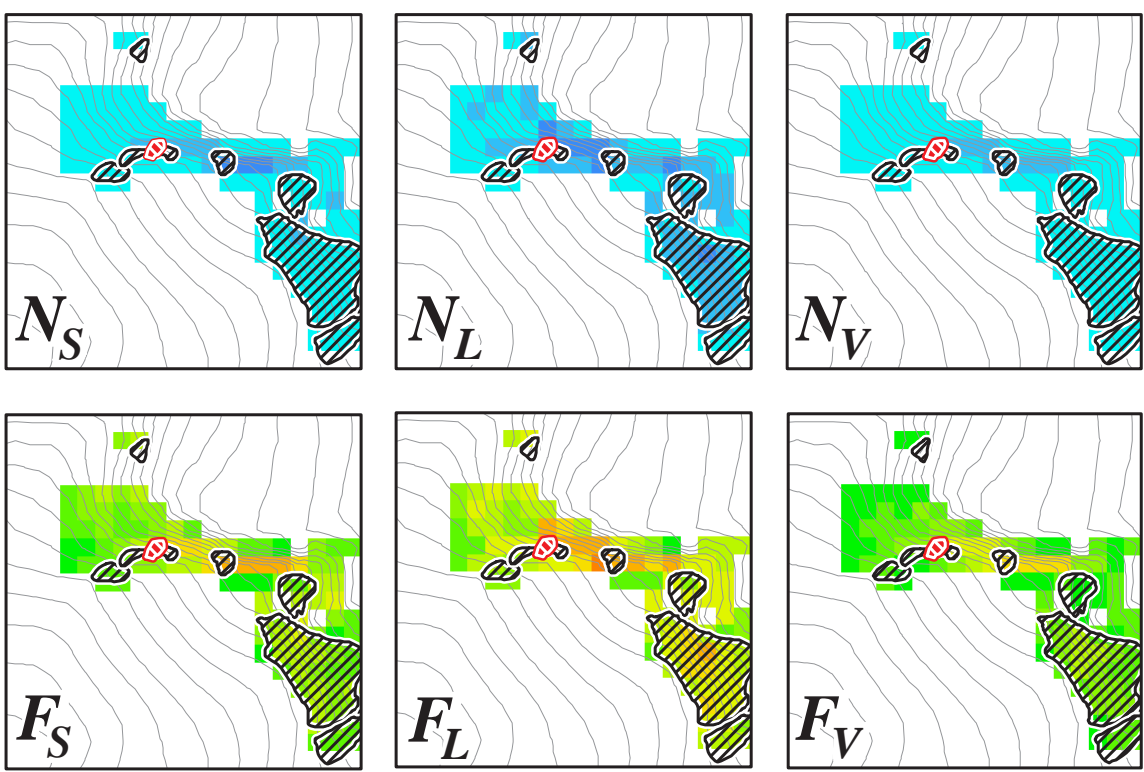

ZII Observed instabilities (detailed field study)

Fig. 7. Maps displaying $N_{S}, N_{L}, F_{S}$ and $F_{L}$ calculated in the area surrounding the Fionnay 1994 rockslide.

$N_{s}, N_{L}, N_{V}, F_{S}, F_{L}$ and $F_{V}$ parameters where calculated (Fig. 7).

The J5 set may generate rockslides in the entire rock face. Cross validation between the presented method and a detailed field study was performed for the cliffs surrounding the rockslide. Only the unstable rock masses liable to slide on J5 discontinuities were sought, because J5 is the main source of instabilities. Their hazard was assessed according to the Matterock method (Rouiller et al., 1998).

This comparison shows good agreement between the observed instabilities and the zones detected using the Matterocking software, being all instabilities located within the potential sliding area. Nevertheless, it should be noted that the area where potentially dangerous J5 discontinuities are found is larger than the area where unstable rock mass is effectively located. This is because although the above method can find potential unstable zones, they do not indicate their precise location. This can be explained by the fact that the presence of sliding planes is necessary but not sufficient for the generation of rock instability. Additional instability factors concern for instance the local morphology (presence of a rocky spur), geology (presence of an undermining weaker layer), tectonics (presence of a nearby fault) or hydrogeology (geometry of the topographic watershed) (Cancelli and Crosta, 1993; Mazzoccola and Hudson, 1996; Dussauge-Peisser, 2002; Baillifard et al., 2003).

Nevertheless, all of the instabilities are located where the number of discontinuities is the highest, and thus where the cell probability is the greatest. Furthermore, the zone con- sisting of multiple small instabilities is also located within the potential sliding area. In this case the considered instabilities are small and so the DEM mesh is too large to detect the local high number of discontinuities.

Another exception is underlined by the cliff bottom, for which the smooth DEM (large mesh) representing the foot of the cliff indicates a lower number of discontinuities than would be indicated by a more detailed DEM.

Although the three methods of counting discontinuities yield similar results, the linear count displayed a slightly smaller area of a high number of discontinuities because the orientation of the cells influences the results. The use of $N_{V}$ or $F_{V}$, highlights more restricted zones than $N_{s}, N_{L}, F_{s}$ or $F_{L}$ because the orientation is taken into account. Nevertheless most of the observed instabilities are included in the higher count zone, taking into account the problems of large cell size smoothing topography for the instabilities located in the north and southwest of the potential sliding zone.

The transformation to probability is interesting since it differentiates the lower values, displaying a relative scale that is more sensitive for the low count values.

\section{Discussion}

The DEM mesh size determines the minimum size of the detected instabilities. It must always be evaluated when doing a study because it defines which of the parameters $F_{s}, N_{s}, N_{L}, N_{V}, F_{V}$ and $F_{L}$ is the most appropriate. 
Maps displaying $N_{s}, N_{L}$, and $N_{V}$ for each mesh represent weighted structures, but in relative terms. They indicate the location where rockslides may occur more frequently. During a survey, these maps can be used to select the locations to be investigated through a detailed field survey.

The use of $F_{S}, N_{s}, N_{L}, N_{V}, F_{V}$ and $F_{L}$ depends on the accuracy of the available data: when $\bar{L}$ or $\bar{T}$ are not well defined, it is better to use $N$ since the use of $F$ has no meaning. The expected values also impose the use of $N$ or $F$ : if all $N$ values are great, it is not useful to calculate the $F$ values since all will yield results near $100 \%(N=1.0, F \approx 63 \%$, for $N=3.0, F \approx 95 \%$ and for $N=4.6, F \approx 99 \%$ ).

For small $N$ values, the estimate of $F$ values will on the contrary give information on the probability of the presence of one discontinuity in each cell. The use of a sliding direction of one discontinuity set $\left(N_{V}\right.$ and $\left.F_{V}\right)$ allows for the detection of locations where larger rock masses can be involved in rockslides, underlining the location where strength on discontinuity is potentially the highest.

In cases where the mean trace length is much longer than the mesh size of the DEM, the use of $F_{S}$ or $F_{V}$ should be avoided. This is because most of the time the calculated probabilities make no physical sense (for example, calculating the probability of finding at least one discontinuity with a trace length of $500 \mathrm{~m}$ in a $25 \times 25 \mathrm{~m}$ cell).

When the trace lengths are long, it is usually possible to calculate $F_{S}$ or $F_{V}$ in areas larger than the mean trace length (for instance along the foot of a cliff or in a rock mass suspected of being unstable). Practically, all calculated values of $N_{s}$ or $N_{V}$ should first be summed in the considered area and the results can then be used to calculate the probabilities $F_{S}$ or $F_{V}$ (probability of finding at least one discontinuity in the area considered).

For $N_{L}$ and $F_{L}$, only $\bar{L}$ must be known, $\bar{T}$ is not taken into account. Thus $N_{L}$ and $F_{L}$, are useful if $\bar{T}$ is even poorly known, since $N_{L}, F_{L}$ can be calculated in each cell mesh of the DEM.

The problem of large DEM cell sizes causing smoothing of the topography and the problem linked to the variations of the orientations of the discontinuity sets can be overcome by introducing a variability in the orientation data. Furthermore, field data are variable. Most of the observed instabilities are located within the area defined by the present method, but this area is larger than the area where unstable rock masses are effectively located (Fig. 7). In order to improve the detected potentially instable areas, the method has to be refined by introducing parameters such as:

- a variability in the discontinuity orientation data;

- mechanical rock properties and modeling, for example as proposed by Gokceoglu et al., (2000) or Günther (2003);

- specific toppling functions, taking into account the shape of the volume delimited by the discontinuity sets.

Those new parameters would refine the estimates of the probability that an unstable rock mass is present $\left(F_{S}, F_{V}\right.$ and $\left.F_{L}\right)$.
As rockslides scars are composite surfaces made of one or more discontinuity sets, the connectivity between discontinuities have also to be quantified in order to refine rockslide hazard assessment.

\section{Conclusion}

Within an area, $H$ and $P_{f}$ can be estimated using a database of ancient rockslide events and making the assumption that the total number of rockslides of a given volume within a period of time must follow a power law theory (Wieczorek et al., 1992; Hantz et al., 2001; Vengeon et al., 2001; Guzzetti et al., 2002). This method allows then the determination of the probable number of rockslide events for a given volume within a period of time and within an area. As shown above, the rockslide hazard $H$ can be assessed using $N_{s}, N_{L}, N_{V}, F_{s}, F_{L}$ or $F_{V}$. The choice of any one of these factors depends on the topography and the characteristics of the discontinuities.

For a given volume, the cells with the highest value of $N_{s}, N_{L}, N_{V}, F_{s}, F_{L}$ and $F_{V}$ parameters may be considered as most likely to produce a rockslide within a period of reference. A rigorous formulation of this method is still under development.

A step further would be to have an automatic estimate by employing software using the probability of the presence of a dangerous structure $\left(F_{S}\right)$ within a given area larger than a topographic cell by counting the mean number $\left(N_{S}\right)$ of discontinuities over that area (Fig. 5b). This method is useful to determine potential large rockslide. This is important for detecting large volumes defined by long, spaced discontinuities.

The presence of unfavorable structural settings can therefore be considered as one important factor to be taken into account in a multi-criterion approach. Several factors have to be incorporated in order to more precisely detect instabilities. Furthermore, an orientation range represented by a cone of a given aperture can be added for the discontinuity set orientation. The zone were toppling is possible can be detected replacing the sliding direction by the perpendicular to the discontinuity, but the frequency values have no direct meaning. Nevertheless more frequent joints isolate more slender elements promoting toppling.

The use of a DEM for the assessment of the probability of the presence of given structures can be refined by using simple stability models as supplementary parameters in hazard estimations (Wu et al., 1996; Scavia and Saeta, 2001).

This probabilistic approach, refined by adding variability and mechanical properties is promising.

The efficiency of the proposed method was proved in several studies applied in Switzerland and Italy (Baillifard et al., 2001). The first step is to identify areas where the number, orientation and geometric characteristics of the discontinuity sets are homogeneous. Following this, a determination of the probability of the presence of potential sliding structures is quite straightforward, leading to a prioritization of potential rockslide sites. 
Acknowledgements. We thank G. Crosta from the University of Milano - Bicocca and A. Günther from the University of Braunschweig for their reviews that greatly improved the manuscript. The second author is supported by the Swiss National Science Foundation (Grant Number 2100-50781.97).

Edited by: P. Reichenbach

Reviewed by: G. B. Crosta and A. Günther

\section{References}

Baillifard, F. : Application de la géologie structurale aux instabilités de type "falaise": description de la méthode Matterock et exemple d'application aux falaises dominant Fionnay (Val de Bagnes, Valais), M. A. Sc. thesis, University of Lausanne, Switzerland, 72, 1998.

Baillifard, F., Jaboyedoff, M., Rouiller, J.-D., and Tosoni, D.: Présentation des méthodes d'études: Matterock, in Interreg 2c: Prévention des mouvements de versants et des instabilités de falaises. Confrontation des méthodes d'études des éboulements rocheux dans l'arc alpin, Final report EU programme Interreg 2c - Falaises, 70-79, 2001

Baillifard, F., Jaboyedoff, M., and Sartori, M.: Rockfall hazard mapping along a mountainous road in Switzerland using a GISbased parameter rating approach, Natural Hazards and Earth System Sciences, 3, 435-442, 2003.

Baroudi, H., Piguet, J. P., Chambon, C., and Asof, M.: Utilization of the block generator "resoblock" to complex geologic conditions in an open pit mine, International Conference on Mechanic of Jointed and Faulted Rock, 18-20 April 1990, Vienna Austria, A.A. Balkema, Rotterdam, 529-536, 1990.

Cancelli, A. and Crosta, G.: Hazard and risk assessment in rockfall prone areas, in: Risk and reliability in ground engineering, edited by Skip, B. O., Thomas Telford, London, 177-190, 1993.

Carrara, A. and Guzzetti, F.: Geographical information systems in assessing natural hazards, Advances in natural and technological hazards, Kluwer Academic Publisher, Dordrecht, 353, 1995.

CREALP: Software for the analysis of spatial distribution of discontinuities in cliffs: Mattercliff, CREALP, Sion, Switzerland, http://www.crealp.ch/, 2003.

Crosta, G.: Evaluating rock mass geometry from photographic images, Rock Mech. Rock Engng., 30, 35-58, 1997.

Crosta, G., Frattini, P., and Sterlacchini, S.: Valutazione e gestione del rischio da frana, Regione Lombardia, Milano, 169, 2001.

Délèze, J.-Y., Jaboyedoff, M., Baillifard, F., and Rouiller, J.-D.: Mattercliff - software for the analysis of spatial distribution of discontinuities in cliffs, EGS - AGU - EUG Joint Assembly, Nice, France, April 2003, abstract EAE03-A-03384, 2003.

Dershowitz, W., Lee, G., Geier, J., Foxford, T., Lapointe, P., and Thomas, A.: FRACMAN Interactive discrete feature data analysis, geometric modeling and exploration simulation - user documentation, Golder Associates Inc. Redmond, USA, 185, 1996.

Dussauge-Peisser, C.: Evaluation de l'aléa éboulement rocheux. Développements méthodologiques et approches expérimentales, Application aux falaises calcaires du $Y$ grenoblois, $\mathrm{PhD}$ thesis, Université Joseph Fourier, Grenoble, France, 222, 2002.

Dussauge-Peisser, C. Helmstetter, A., Grasso, J.-R., Hantz, D., Desvarreux, P., Jeannin, M., and Giraud, A.: Probabilistic approach to rockfall hazard assessment: potential of historical data analysis, Natural Hazards and Earth System Sciences, 2, 15-26, 2002.
Ecole des Mines de Nancy: Resoblok - notice d'utilisation (Programme de représentation géométrique des réseaux de fractures), LAEGO - Ecole des Mines de Nancy, 92, 2000.

Froldi, P.: Digital terrain model to assess geostructural features in near vertical cliffs, Bull. Eng. Geol. Env., 59, 201-206, 2000.

Giani, G. P.: Rock slope stability analysis, A.A. Balkema, Rotterdam, 361, 1992.

Gokceoglu, C., Sonmez, H., and Ercanoglu, M.: Discontinuity controlled probabilistic slope failure risk maps of the Altindag (settlement) region in Turkey, Eng. Geol., 55, 277-296, 2000.

Günther, A.: SLOPEMAP: programs for automated mapping of geometrical and kinematical properties of hard rock hill slopes, Computers and Geosciences, 29/7, 865-875, 2003.

Gupta, S. K., Saha, A. K., Arora, M. K., and Kumar, A.: Landslide hazard zonation in a part of the Bhagirati Valley, Garhwal Himalayas, using integrated remote sensing - GIS, Himalayan Geology, 20/2, 71-85, 1999.

Guzzetti, F., Carrara, A., Cardinali, M., and Reichenbach, P.: Landslides hazard evaluation: a review of current techniques and their application in a multi-scale study, Central Italy, Geomorphology, 31, 181-216, 1999

Guzzetti, F., Malamud, B. D., Turcotte, D. L., and Reichenbach, P.: Power-law correlations of landslide areas in central Italy, Earth and Planetary Science Letters, 195, 169-183, 2002.

Hantz, D., Vengeon, J.-M., and Dussauge, C.: Approche historique, géomécanique et probabiliste de l'aléa éboulement rocheux, 15 ème congrès français de mécanique, Nancy, France, 1-6, 2001.

Hoek, E. and Bray, J.: Rock slope engineering, revised third edition, $\mathrm{E}$ and FN Spon, London, 358, 1981.

Jaboyedoff, M., Philippossian, F., Mamin, M., Marro, C., and Rouiller, J.-D.: Distribution spatiale des discontinuités dans une falaise, Rapport de travail PNR31, VDF Publisher, Zürich, 90, 1996.

Jaboyedoff, M., Baillifard, F., Marro, C., Philippossian, F., and Rouiller, J.-D.: Detection of rock instabilities: matterock methodology, in: Joint Japan-Swiss seminar on impact load by rock falls and design of protection structures, Kanazawa, Japan, 4-7 October 1999, edited by Masuya, H. and Labiouse, V., 1319, 1999.

LaPointe, P.-R. and Hudson, J.-A.: Characterization and interpretation of rock mass joint patterns, Special Paper - Geological Society of America, (GSA), 37, 1985.

Mauldon, M., Dunne, W. M., and Rohrbaugh, Jr., M. B.: Circular scanlines and windows: new tools for characterizing the geometry of fractures traces, J. of Struct. Geol., 23, 247-258, 2001.

Mazzoccola, D. F. and Hudson, J. A.: A comprehensive method of rock mass characterization for indicating natural slope instability, Quarterly Journal of Engineering Geology, 29, 37-56, 1996.

Meentemeyer, R. K. and Moody, A.: Automated mapping of conformity between topographic and geological surfaces, Computers and Geosciences, 26/7, 815-829, 2000.

Montgomery, D. R., Dietrich, W. E., and Sullivan, K.: The role of GIS in watershed analysis, in: Landform monitoring, modeling and analysis, edited by Lane, S. N., Richards, K. S., and Chandler, J. H., J. Wiley and Sons, New-York, 241-262, 1998.

Pack, R. T., Tarboton, D. G., and Goodwin, C. N.: The SINMAP approach to terrain stability mapping, Proceedings 8th Congress of the International Association of Engineering Geology, Vancouver, British Columbia, Canada, 21-25 September 1998, 11571165, 1998. 
Pahl, P. J.: Estimating the mean length of discontinuity traces, Int. J. Rock Mech. Min. Sci. and Geomech. Abstr., 18, 221-228, 1981.

Priest, S. D.: Discontinuity analysis for rock engineering, Chapman and Hall, London, 473, 1993.

Priest, S. D. and Hudson, J. A.: Estimation of discontinuity spacing and trace length using scanline surveys, Int. J. Rock Mech. Min. Sci. and Geomech. Abstr., 18, 183-197, 1981.

Rocscience: Graphical and statistical analysis of orientation data program: Dips. Rocscience, Toronto, Canada. (http://www.rocscience.com/).

Rouiller, J.-D., Jaboyedoff, M., Marro, C., Phlippossian, F., and Mamin, M.: Pentes instables dans le Pennique valaisan. Matterock: une méthodologie d'auscultation des falaises et de détection des éboulements majeurs potentiels, Rapport final du PNR31, VDF Publisher, Zürich, 239, 1998.

Scavia, C. and Saeta, V.: Metodo meccanico-probabilistico per l'analisi della stabilità dei pendii in roccia., in: Interreg 2c: Prévention des mouvements de versants et des instabilités de falaises. Confrontation des méthodes d'études des éboulements rocheux dans l'arc alpin, Final report EU programme Interreg 2c - Falaises, 116-120, 2001.

Selby, M. J.: Hillslope materials and processes, second edition, Oxford University Press, Oxford, 451, 1993.

Starzec, P. and Andersson, J.: Probabilistic predictions regarding key blocks using stochastic discrete fracture networks - example from a rock caverne in south-east Sweden, Bull. Eng. Geol. Env., 61, 363-378, 2002.
Terzaghi, R. D. : Sources of error in joint surveys, Geotechnique, 15, 287-304, 1965.

Thomas, A., Pienau, A., and Blin-Lacroix, J.-L.: Determination of a spatial fracture network, International Journal of Numerical and Analytical Methods in Geomechanics, 11, 381-390, 1987.

Vengeon, J. M., Hantz, D., and Dussauge C.: Prédictibilité des éboulements rocheux: approche probabiliste par combinaison d'études historiques et géomécaniques, Rev. Fr. de Géotech., 9596, 143-154, 2001.

Wagner, A., Leite, E., and Olivier, R.: Rock and debris-slides risk mapping in Nepal - A user-friendly PC system for risk mapping, in: Landslides, Proceedings of the 5th International Symposium on Landslides, Lausanne, Switzerland, 10-15 July 1988, edited by Bonnard, C., A.A. Balkema, Rotterdam, 2, 1251-1258, 1988.

Wieczorek, G. F., Snyder, J. B., Alger, C. S., and Isaacson, K. A.: Yosemite historical rockfall inventory, U.S Geol. Surv. Open File Rep., 92-387, 38, 1992.

Wu, T. H., Tang, W. H., and Einstein, H. H.: Landslide hazard and risk assessment, in: Landslides: investigation and mitigation, special Report 247, edited by Turner, A. K. and Schuster, R. L., Transportation Research Board, 106-120, 1996. 